\title{
Improving the monitoring of conservation programmes: lessons from a grant-making initiative for threatened species
}

\author{
Alessandro Badalotti, Lauravan Galen \\ JeAn-Christophe Vié and P. J. Stephenson
}

\begin{abstract}
Many conservation projects have weak capacity to monitor their target species and the threats they face, compromising adaptive management. We assessed 74 vertebrate and plant conservation projects worldwide that were supported by the SOS-Save Our Species Programme (now IUCN Save Our Species) during 2012-2015. Our aim was to determine how and where monitoring efforts were focused, identify trends in data availability and make recommendations for improvement. Project managers reported more of a decrease in threats $(73 \%)$ and improved habitat conditions (68\%) than positive population changes (19\%), primarily because of the focus of their objectives and limited time to collect population data. More population data were collected on reptiles and amphibians than mammals and birds, contrary to global trends. This probably reflects a greater focus of mammal and bird projects on improving habitats or reducing threats. There were geographical differences in data availability. Lessons learnt that could be applied to future project portfolios include: a common strategic framework should be developed, along with a set of common indicators against which projects can align and demonstrate their contributions; more guidance and capacity building support should be provided to grantees; and a greater allocation of project budgets should be dedicated to monitoring.
\end{abstract}

Keywords Biodiversity, conservation evidence, impact, IUCN, monitoring, results-based management, species

\footnotetext{
Alessandro BADALOTTI ${ }^{*} \dagger$ (Corresponding author) and JeAn-Christophe ViÉł Global Species Programme and IUCN Save Our Species, IUCN, Gland, Switzerland. E-mail abadalotti@hotmail.com

LAURA VAN GaLenS\$ School of Natural Sciences, University of Tasmania, Hobart, Tasmania, Australia

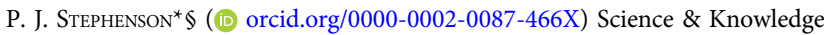
Unit, IUCN, Gland, Switzerland

*Also at: IUCN Species Survival Commission Species Monitoring Specialist Group, Gingins, Switzerland

†Current address: Fondation Segré, Geneva, Switzerland $\ddagger$ Current address: Fondation Franklinia, Geneva, Switzerland

$\S$ Current address: Laboratory for Conservation Biology, Department of Ecology \& Evolution, University of Lausanne, Lausanne, Switzerland

ๆ|Also at: Department of Botany, University of Otago, Dunedin, New Zealand

Received 9 September 2019. Revision requested 14 February 2020.

Accepted 15 June 2020. First published online 11 June 2021.
}

\section{Introduction}

G lobal trends demonstrate that, in spite of continued conservation efforts and new initiatives and organizations, biodiversity continues to decline while threats and pressures increase (e.g. Secretariat of the Convention on Biological Diversity, 2014; WWF, 2018; Diaz et al., 2019). Conservation resources remain limited (McCarthy et al., 2012), so it is more important than ever for conservation programme managers to monitor their impacts, outcomes and outputs, to learn and share lessons and to improve the effectiveness of their conservation strategies. However, capacity for monitoring in conservation projects remains weak, and results-based or evidence-based management is not applied as often as required, especially in biodiversity-rich countries (e.g. Stephenson et al., 2015a, 2017a, in press; Schmeller et al., 2017). As a result, data on species, their habitats and threats are inadequate for effective conservation management (Crees et al., 2016; Stephenson et al., 2017b). Here we examine a portfolio of species conservation projects to try to identify lessons and make recommendations for improving project and portfolio monitoring.

SOS-Save Our Species was created in 2010 as a joint initiative of IUCN, the Global Environment Facility and the World Bank, supported by multiple donors. Its objective is to ensure the long-term survival of threatened species, their habitats and the people who depend on them. Backed by the expertise of the IUCN Species Survival Commission, Save Our Species acts as the conduit for aggregating and distributing funds to threatened species conservation projects globally. Projects are funded through small to medium-sized grants (USD 25,000-700,000) lasting 1-2 years and selected through multiple competitive calls for proposals, each focussing on discrete taxonomic and geographical priorities and informed by the IUCN Red List of Threatened Species (IUCN, 2020). During the first 7 years of implementation (2010-2016) Save Our Species funded 91 projects through Threatened Species Grants. The focus of the different calls for proposals was determined by the Save Our Species technical advisory group and used a rotational approach in terms of taxonomic groups and regions supported over time. Taxonomic groups were selected among those that had been thoroughly assessed on the IUCN Red List of Threatened Species, with an attempt to 
TABLE 1 Taxonomic groups addressed by Save Our Species projects.

\begin{tabular}{ll}
\hline Class/grouping & Family/Order \\
\hline Mammalia & $\begin{array}{l}\text { Bovidae, Cercopithecidae, Delphinidae, Dugongidae, Elephantidae, Felidae, Giraffidae, Hippopotamidae, Hominidae, } \\
\text { Hylobatidae, Macropodidae, Phocidae, Phocoenidae, Platanistidae, Pteropodidae, Rhinocerotidae, Suidae, } \\
\text { Tachyglossidae, Trichechidae }\end{array}$ \\
& $\begin{array}{l}\text { Accipitridae, Anatidae, Ardeidae, Cacatuidae, Cathartidae, Heliornithidae, Megapodiidae, Otididae, Psittacidae, } \\
\text { Scolopacidae, Thraupidae, Threskiornithidae }\end{array}$ \\
Reptilia & Testudines, Crocodylia \\
Amphibia & Anura, Caudata, Gymnophiona \\
Fish & Atheriniformes, Carcharhiniformes, Cypriniformes, Lamniformes, Osmeriformes, Rajiformes, Siluriformes \\
Plants & Cupressaceae, Pinaceae, Podocarpaceae, Zamiaceae
\end{tabular}

diversify groups as much as possible. This is how taxonomic groups often neglected by other funding bodies, such as sharks and rays, cycads and conifers, were included. Projects had to contribute towards threatened species conservation and were then classified according to a suite of defined conservation actions on threatened species (Salafsky et al., 2008), namely land/water protection, land/water management, species management, education and awareness, law and policy, livelihoods, and economic and other incentives. The resulting portfolio contributed to the protection of 250 threatened species and supported 78 NGOs operating in 65 countries. During this period Save Our Species disbursed USD 10 million in species conservation grants and leveraged a further USD 13 million.

In this review we assess and synthesize the major findings of the Save Our Species Threatened Species Grant portfolio, to determine how and where monitoring efforts were focused, identify trends in data availability and make recommendations for improvements to project and portfolio monitoring. We examined the extent to which projects reported changes in the population status of target species, improved the quality of critical habitats and mitigated threats. We also examined what proportion of projects conducted monitoring to quantify their results, and identified any taxonomic or geographical trends.

\section{Methods}

A total of 74 projects were analysed from the Save Our Species portfolio, comprising those projects awarded a Threatened Species Grant prior to 2015 that had completed their reporting. We extracted information regarding project impacts on population status, habitat quality and threats from project reports, and noted whether they undertook monitoring to provide evidence to support their results. Projects were said to have undertaken monitoring if they carried out any steps to collect data, either to assess project impact directly (e.g. counts of population numbers, counts of dead individuals) or indirectly through a proxy (e.g. nest counts as an indication of population numbers, surveys of communities to indicate wildlife consumption, changes in the amount of poaching gear observed on patrols to indicate illegal activity).

\section{Results}

Of the projects assessed, $42 \%$ were in Asia (14 countries), $40 \%$ in Africa (23 countries), $15 \%$ in Latin America (nine countries) and $3 \%$ in Oceania (two countries). Projects focused on a wide range of taxa including mammals $(52 \%$ of projects), birds $(12 \%)$, fish (11\%), plants $(11 \%)$, reptiles $(7 \%)$ and amphibians ( $7 \%$ ) (Table 1). Thirty-eight per cent of projects included actions focused on habitat conservation, and $95 \%$ on tackling threats.

\section{Population changes}

Reports demonstrated project successes in conserving species populations by increasing or stabilizing numbers, such as the case of the hirola Beatragus hunteri in Kenya, the California condor Gymnogyps californianus in Mexico, the southern river terrapin Batagur affinis in Cambodia and the endemic cycad Encephalartos whitelockii at its only known location in Uganda. Some projects working on species such as the Bengal tiger Panthera tigris tigris in the Sundarbans of Bangladesh, also noted that a reduction in the rate of decline was considered a success. Some other projects reported a decrease or a continued decrease in their target populations or in their population trends, such as in the case of the vaquita Phocoena sinus in Mexico, the longbilled vulture Gyps indicus and the slender-billed vulture Gyps tenuirostris in India and the great and scalloped hammerhead Sphyrna mokarran and Sphyrna lewini in Latin America.

Data derived from monitoring were available for $61 \%$ of target populations and from 47 of $74(64 \%)$ of the projects. Based on this evidence, $19 \%$ of target populations were reported to have been positively affected (i.e. populations had increased in size or the rate of decrease had slowed), 

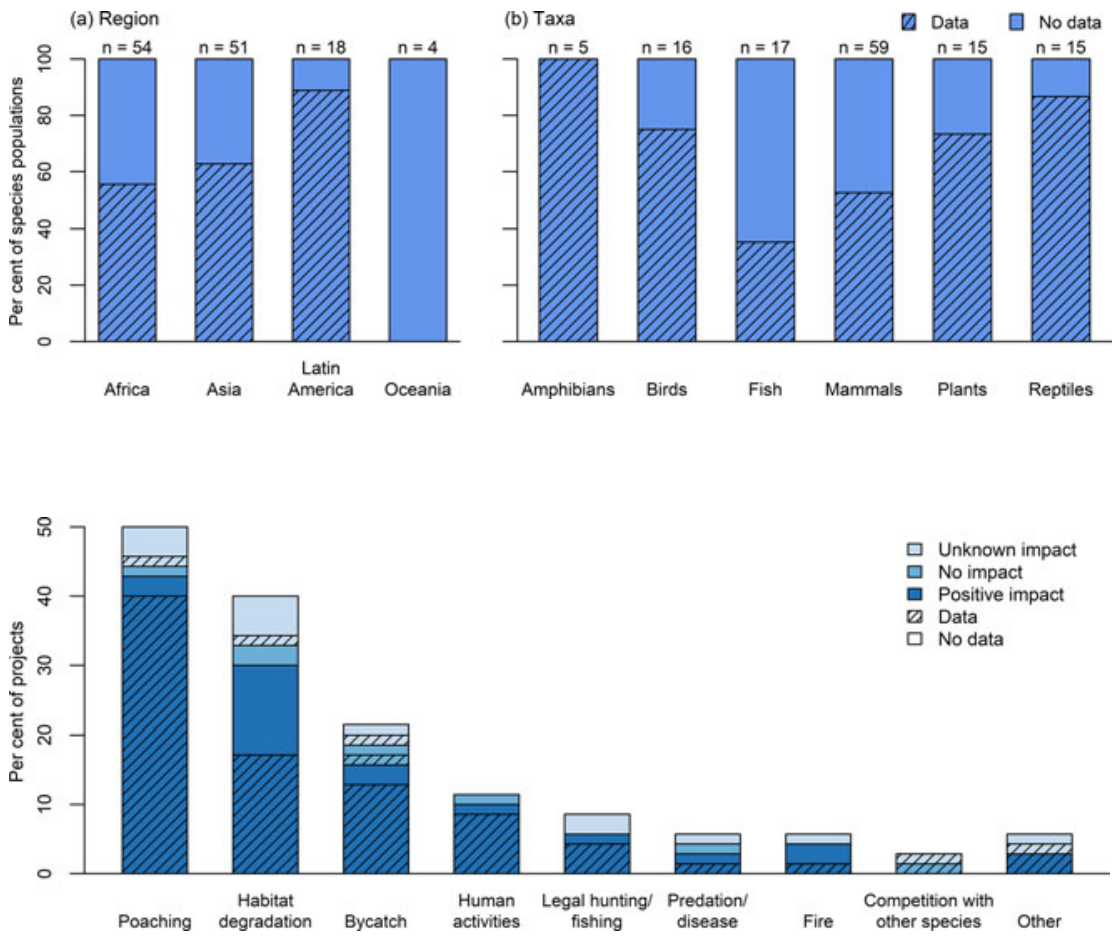

ㅁ Unknown impact 므o impact - Positive impact $\square$ Data $\square$ No data other species
FIG. 1 The per cent of species populations targeted within (a) each region and (b) each taxonomic group for which some form of monitoring was undertaken to provide evidence of the trends reported. Values for $\mathrm{n}$ indicate the total number of populations targeted within that region or taxonomic group.
$18 \%$ had remained stable, and the change in $63 \%$ was unknown or not specified. Reports suggested the paucity of data was predominantly a result of a lack of monitoring, absence of an initial baseline, the short timeframe of the project, or the fact that influencing population numbers was not an objective of the project (so no resources were allocated to assessing population change). Data were collected for a higher per cent of amphibian and reptile populations than other taxa, and for a higher proportion of Latin American species populations (84\%) than in other regions (Fig. 1). Amphibian, fish and plant projects mostly reported no change in population numbers or that impact was unknown. Plant projects generally focussed on collecting baseline population data.

\section{Critical habitat}

Successes in conserving habitats included projects implemented in the Mount Rungwe and the Livingstone Mountains forests of Tanzania, in the Olifants-Doring and the Breede-Tradouw river systems in the Cape Floristic region of South Africa, and in the Ujung Kulon National Park in Indonesia. Although only $29 \%$ of habitatfocused projects ( 8 of 28 ) conducted active monitoring, $68 \%$ claimed some success in improving habitat condition, and $29 \%$ in increasing the total area of habitat available. Half of habitat-focused mammal projects and $40 \%$ of bird projects collected data; no evidence was provided for projects focusing on other taxa. A higher per cent of habitat-focused
FIg. 2 The per cent of projects (of those that focused on threats) addressing each type of threat, their reported impact on that threat, and whether monitoring was undertaken to provide data to support their result. Human activities refers to ecotourism and recreation, retaliatory killing/human-wildlife conflict, off-road driving and infrastructure development. Four projects addressed other threats, including powerlines/wind turbines, poisoning, germination barriers and climate change. projects in Asia (56\%) provided data than in Africa (21\%), and no data were provided in Latin America or Oceania. Sixty-eight per cent of projects reported improved habitat condition from planting trees or removing alien invasive species. Although some quantified the success of their actions (e.g. by assessing seedling survival or regrowth of native species), most did not, and many stated that the timeframe was too short to demonstrate results. The remaining $32 \%$ of projects that reported improved habitat condition had created new reserves or strengthened existing protection (e.g. increasing patrols to reduce poaching or enforcing stricter regulations on fishers), but none of these projects determined how this increased protection influenced habitat quality.

\section{Reducing threats}

Successes in reducing threats included reduction in poaching in various protected areas in Africa and Asia, reduction in bycatch of dugongs Dugong dugon, sharks (Sphyrna spp.) and manta rays (Mobula spp.), reduction in predation at the Ishaqbini Hirola Community conservancy in Kenya, and reduction in habitat degradation in the Mpanga catchment in Uganda and in the newly created community conservancies in Gilgit Baltistan in northern Pakistan.

Ninety-five per cent of projects (70 of 74) aimed to reduce identified threats to target species. Eight main threats were addressed across the portfolio (Fig. 2), with poaching and habitat degradation (e.g. from deforestation, agriculture, 

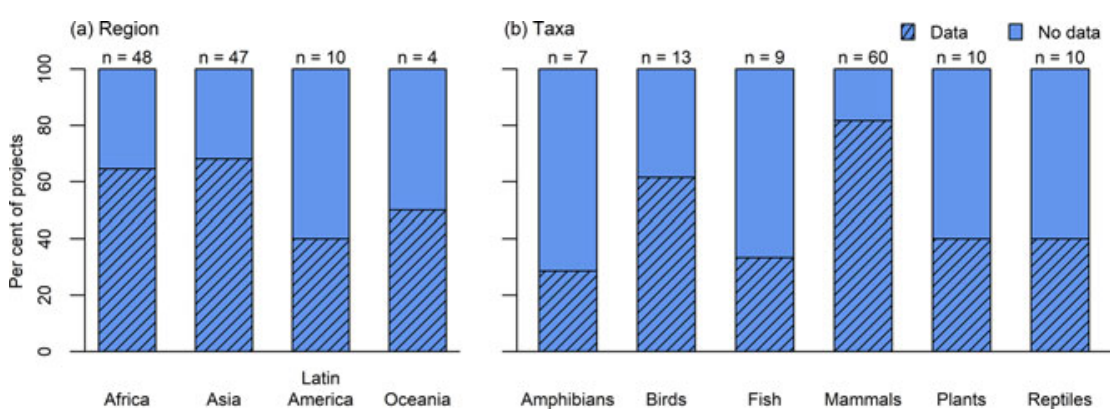

FIG. 3 The per cent of projects that aimed to address threats within (a) each region and (b) each taxonomic group for which data were provided as evidence for their reported impact. $\mathrm{n}$ indicates the number of threats that were targeted within each region and taxonomic group. erosion or mining) the most common. Seventy-three per cent of the threats addressed were reportedly reduced, the outcome was unknown for $19 \%$ (mainly because of lack of monitoring or the inability to collect sufficient data over the project timeframe), and $8 \%$ remained unchanged.

Evidence to support threat reduction was collected for $63 \%$ of threats addressed. Most threat monitoring was undertaken for projects targeting mammals and birds and more often for projects in Asia and Africa than in Oceania or Latin America (Fig. 3). Where data were presented to support results, a reduction was measured or assumed for $72 \%$ of threats to mammals, $60 \%$ of threats to reptiles, $31 \%$ of threats to birds, $30 \%$ of threats to plants, $29 \%$ of threats to amphibians and $22 \%$ of threats to fish. Evidence was collected through direct population assessments to determine the impact of the reduced threat on numbers, but more commonly through monitoring the success of the mitigation efforts (e.g. quantifying traffickers arrested, changes in poaching incidences, or bycatch released). Sometimes project reports provided statistics on activities carried out to reduce threats, such as poaching gear confiscated or the amount of safe fishing gear distributed, rather than any actual or proxy measure of a reduction in threat.

\section{Comparison of data across project types}

Monitoring was undertaken for $61 \%$ of target populations, $29 \%$ of target habitats and $63 \%$ of target threats. A total of 14 projects (19\%) conducted no monitoring at all. Projects had more success demonstrating reductions in threats ( $73 \%$ of threats addressed were reported to be reduced) and improvements in habitat (68\%) than positive population changes (19\%). The absence of monitoring in a significant proportion of projects meant many managers lacked the means to quantify whether their objectives had been achieved, and therefore success levels were difficult to determine. Geographical and taxonomic trends for monitoring population numbers were different from the trends for monitoring habitats and threats. Projects conducted in Africa and Asia and projects focusing on mammals and birds undertook the highest levels of monitoring for habitat changes and threat reduction. However, to quantify impact on population numbers, Central and South American projects and projects focusing on amphibians and reptiles undertook the most monitoring.

\section{Discussion}

Most projects supported by Save Our Species produced at least some evidence of tangible results in conserving populations of threatened species, improving their habitats and reducing threats, confirming previous evidence that targeted conservation interventions can improve species recovery (e.g. Schipper et al., 2008; Hoffmann et al., 2010). However, data to justify reported results were often limited. Populations were generally monitored less than threats or habitats across the project portfolio, reflecting broader trends for projects to report more on responses and outcomes than on impacts (Stephenson et al., 2015a; Stephenson \& Ellis, 2017).

However, monitoring across the portfolio was less extensive than expected, reflecting trends elsewhere for inadequate monitoring and data collection in conservation projects (Stem et al., 2005; Gibbons et al., 2011; Schmeller et al., 2017; Stephenson et al., 2017a, in press). Weak monitoring and knowledge sharing reduces potential for projects to scale-up efforts (Murcia et al., 2016), and can be expected to reduce the value of a project in convincing and inspiring donors, policy makers and other stakeholders of the value of conservation. Conversely, there is some evidence that policy recognition of a species, in the form of species recovery plans, may lead to higher quality monitoring (Scheele et al., 2019).

Removing threats to species is likely to improve population status (Crees et al., 2016) but more effort needs to be made in monitoring and mitigating threats to quantify the real impact on target populations. In future, data on actions (such as poaching gear confiscated or the amount of safe fishing gear distributed) needs to be accompanied by information on concrete outcomes, such as changes in the number of poaching incidences or the number of animals killed or released alive from bycatch. Measuring the impact of conservation interventions also ideally requires counterfactuals to assess what might have happened had action not been taken (e.g. Hoffmann et al., 2015; Akçakaya et al., 2018; 
Stephenson, 2019). Therefore, grantees could be encouraged to compare results in their project with neighbouring populations of the target species to compare status and threats.

In projects funded by Save Our Species there were more data for amphibian and reptile populations than for birds and mammals, in contrast to two global databases, the Living Planet Index and the Global Biodiversity Information Facility (McRae et al., 2017; Troudet et al., 2017), and a country-wide assessment (Scheele et al., 2019). The reason for this discrepancy could be that in the Save Our Species portfolio more of the mammal and bird projects focused on habitat conservation or threats and thus data on habitats or threats, rather than on populations, were the focus of the limited monitoring efforts. In addition, projects focused on Critically Endangered amphibians and reptiles for which the small or range-restricted population is well known.

Although tropical countries are known to have fewer data on biodiversity than temperate countries (e.g. McRae et al., 2017), there are few direct comparisons between continents. An analysis of the Global Biodiversity Information Facility database suggested the biggest gaps in digitally accessible information on terrestrial vertebrates are in Asia ( $48 \%$ of grid cells with no data), followed by Africa (35\%) and South America (21\%) (Meyer et al., 2015). Asia is also slightly weaker than South America on biodiversity research outputs (measured by publications), with Africa being stronger (Velasco et al., 2015), but this assessment simply underlines the general trend for more capacity for data collection and use in Europe and North America. A more detailed analysis of gaps in monitoring data and capacity is required (Stephenson, 2018).

The reasons why some Save Our Species projects were weaker on monitoring and data use was often not apparent from the reports. This generally appears to have been because of the lack of baselines against which to compare project results and the absence of a specific project budget or project actions assigned to monitoring. Other possible explanations include limited project team capacity for monitoring or that monitoring data became available only after Save Our Species funding had ended and therefore data were not communicated to Save Our Species. Although short-term projects may not be able to collect much data, or change may happen after the project ends, in particular for long-lived species, some evidence of progress towards project goals is required if best practices are to be followed. Species conservation programmes could therefore help by allocating a fixed proportion of the budget for monitoring and including, where feasible, resources for post-project monitoring (Stephenson, 2019). In the case of plant species or habitat restoration projects, fixed point photograph techniques could be used to provide a cheap way of monitoring impact. Project portfolios should also move towards longerterm investments in projects with feasible monitoring plans if reductions in threats and improvements in species status are to be expected and measured, as these often take a number of years to materialize. For example, an internal review of WWF conservation programmes globally demonstrated a period of at least 10 years is usually required to show significant impact (PJS, unpubl. data). However, given budgets are often strained, the most common feasible solution will be for smaller projects to measure only pressures, from which assumptions about impacts on species populations can be made if an appropriate theory of change is in place (Dickson et al., 2017; Stephenson, 2019). Grantees also need support in accessing relevant guidance and training on setting up monitoring plans, using frameworks such as the Open Standards for the Practice of Conservation (CMP, 2013) and PRISM (Dickson et al., 2017).

Weak individual project monitoring also caused challenges in assessing the impacts and outcomes of the portfolio as a whole, especially as there was no simple mechanism for aggregating results across the portfolio. This was compounded by the fact the portfolio focused on a wide diversity of actions across a wide diversity of taxa and geographical areas, making it hard to assess which strategies worked. The use of common measures or indicators across projects can facilitate aggregation of results and allow projects to demonstrate their contributions to higherlevel goals (e.g. Stephenson \& Reidhead, 2018), especially if the pressure-state-response-benefit model is followed to capture results at different levels (Stephenson, 2019). Based on lessons learnt, Save Our Species has recently adopted this approach (A. Nieto, pers. comm., 2020). Other possibilities to increase monitoring at the individual project level should be piloted. Options include the continued collaboration between a donor and a former grantee after the completion of support for an ongoing project to share additional monitoring data at regular intervals. Building capacity amongst grantees for effective monitoring and, where appropriate, using projects to establish suitable citizen science monitoring schemes, may also help ensure long-term data collection (Stephenson et al., in press).

Conservation projects need to share lessons on what does and does not work (Stephenson et al., 2015b) and this sharing should include both donors and practitioners. Our assessment of the Save Our Species programme demonstrates the challenges of monitoring the results of a large portfolio of diverse, short-term conservation projects, tackling multiple threats to multiple taxa. In particular, supporting diverse taxa of plants and animals created challenges in identifying common indicators. The second phase of Save Our Species, from 2017, received longer-term funding and is more taxonomically and geographically focused, with initiatives on lemurs, African carnivores and gibbons, offering the opportunity for more harmonized monitoring frameworks across the project portfolio. Concrete actions to be considered for developing a robust monitoring framework for such portfolios in future include: ensuring projects set appropriate indicators for the scale and focus of their project, including 
some common measures that demonstrate delivery of project results and allow aggregation; offering capacity building support to grantees in project planning and monitoring; the construction and maintenance of a central project database on a platform that facilitates data analysis and the production of data products such as maps and dashboards (as has been done by several conservation organizations: e.g. Han et al., 2014; Stephenson et al., 2015a); a structured process for ensuring data from projects are shared and, where appropriate, included in key global databases, such as the IUCN Red List, and into relevant national and regional databases.

There is a growing movement to improve resultsbased management of conservation projects (e.g. Ferraro \& Pattanayak, 2006; Dicks et al., 2014; Stephenson, 2019), and we urgently need to fill gaps in biodiversity data for tropical countries (Stephenson et al., 2017b). If we do not invest more effort in monitoring, we will continue to have a limited understanding of the difference our work makes to biodiversity. If, however, more conservation projects and their donors allocate an adequate proportion of their resources to monitoring, we would be able to demonstrate more clearly which strategies work well and which not so well, and adapt or replicate actions accordingly. Improved monitoring of threatened species, their habitats and threats will therefore ultimately lead to improved conservation impact.

Acknowledgements We thank Save Our Species grant recipients who submitted reports; colleagues in IUCN for their support; and Tom Brooks who hosted PJS and LvG at IUCN. The Save Our Species programme received funding from several donors but this research received no specific grant from any funding agency, commercial or not-for-profit sectors.

Author contributions Programme implementation: $\mathrm{AB}, \mathrm{J}-\mathrm{CV}$; conception and design of review: $\mathrm{AB}, \mathrm{PJS}$; data collation: $\mathrm{AB}, \mathrm{LvG}$; data analysis: LvG; writing: $A B, P J S$, with input from all authors.

Conflicts of interest All four authors have worked at or with IUCN and two have worked on the Save Our Species initiative. AB worked for IUCN during January 2011-May 2020 and was Save Our Species Coordinator during January 2011-December 2017. LvG was an intern with the IUCN Species Survival Commission Species Monitoring Specialist Group during May-June 2017. J-CV worked for IUCN during January 2000-December 2017 and was Save Our Species Director during October 2010-December 2017. PJS worked for the IUCN Science and Knowledge Unit during January 2017-January 2018. The authors have endeavoured to demonstrate the weaknesses and failings in Save Our Species monitoring as well as the successes, and hope by sharing their experiences other such programmes will learn relevant lessons.

Ethical standards This research abided by the Oryx guidelines on ethical standards.

\section{References}

Akçakaya, H.R., Bennett, E.L., Brooks, T.M., Grace, M.K., Heath, A., Hedges, S. et al. (2018) Quantifying species recovery and conservation success to develop an IUCN Green List of species. Conservation Biology, 32, 1128-1138.

CMP (Conservation Measures Partnership) (2013) Open Standards for the Practice of Conservation, Version 3. Conservation Measures Partnership, Bethesda, USA.

Crees, J.J., Collins, A.C., Stephenson, P.J., Meredith, H.M.R., Young, R.P., Howe, C. et al. (2016) A comparative approach to assess drivers of success in mammalian conservation recovery programs. Conservation Biology, 30, 694-705.

Diaz, S., Settele, J., Brondízio, E., Ngo, H.T., Guèze, M., Agard, J. et al. (2019) Summary for Policymakers of the Global Assessment Report on Biodiversity and Ecosystem Services. IPBES, Bonn, Germany.

Dicks, L.V., Walsh, J.C. \& Sutherland, W.J. (2014) Organising evidence for environmental management decisions: a ' 4 S' hierarchy. Trends in Ecology and Evolution, 29, 607-613.

Dickson, I.M., Butchart, S.H.M., Dauncey, V., Hughes, J., Jefferson, R., Merriman, J. et al. (2017) PRISM - Toolkit for Evaluating the Outcomes and Impacts of Small/Medium-Sized Conservation Projects. Version 1. Cambridge Conservation Initiative, Cambridge, UK.

Ferraro, P.J. \& Pattanayak, S.K. (2006) Money for nothing? A call for empirical evaluation of biodiversity conservation investments. PLOS Biology, 4, e105.

Gibbons, D.W., Wilson, J.D. \& Green, R.E. (2011) Using conservation science to solve conservation problems. Journal of Applied Ecology, 48, 505-508.

Han, X., Smyth, R.L., Young, B.E., Brooks, T.M., De Lozada, A.S., BuBB, P. et al. (2014) A biodiversity indicators dashboard: addressing challenges to monitoring progress towards the Aichi biodiversity targets using disaggregated global data. PLOS ONE, 9, e112046.

Hoffmann, M., Duckworth, J.W., Holmes, K., Mallon, D.P., Rodrigues, A.S. \& Stuart, S.N. (2015) The difference conservation makes to extinction risk of the world's ungulates. Conservation Biology, 29, 1303-1313.

Hoffmann, M., Hilton-Taylor, C., Angulo, A., Böhm, M., Brooks, T.M., Butchart, S.H.M. et al. (2010) The impact of conservation on the status of the world's vertebrates. Science, 330, 1503-1509

IUCN (2020) The IUCN Red List of Threatened Species. Version 2020-1. iucnredlist.org [accessed 13 May 2020].

McCarthy, D.P., Donald, P.F., Scharlemann, J.P., Buchanan, G.M., Balmford, A., Green, J.M. et al. (2012) Financial costs of meeting global biodiversity conservation targets: current spending and unmet needs. Science, 338, 946-949.

McRae, L., Deinet, S. \& Freeman, R. (2017) The diversity-weighted living planet index: controlling for taxonomic bias in a global biodiversity indicator. PLOS ONE, 12, e0169156.

Meyer, C., Kreft, H., Guralnick, R. \& Jetz, W. (2015) Global priorities for an effective information basis of biodiversity distributions. Nature Communications, 6, 8221.

Murcia, C., Guariguata, M.R., Andrade, Á., Andrade, G.I., Aronson, J., EscobAr, E.M. et al. (2016) Challenges and prospects for scaling-up ecological restoration to meet international commitments: Colombia as a case study. Conservation Letters, 9, 213-220.

Salafsky, N., Salzer, D., Stattersfield, A.J., Hilton-Taylor, C., Neugarten, R., Butchart, S.H.M. et al. (2008) A standard lexicon for biodiversity conservation: unified classifications of threats and actions. Conservation Biology, 22, 897-911.

Scheele, B.C., Legge, S., Blanchard, W., Garnett, S., Geyle, H., Gillespie, G. et al. (2019) Continental-scale assessment reveals inadequate monitoring for threatened vertebrates in a megadiverse country. Biological Conservation, 235, 273-278. 
Schipper, J., Chanson, J.S., Chiozza, F., Cox, N.A., Hoffmann, M., Katariya, V. et al. (2008) The status of the world's land and marine mammals: diversity, threat, and knowledge. Science, $322,225-230$.

Schmeller, D.S., Böhm, M., Arvanitidis, C., Barber-Meyer, S., Brummitt, N., Chandler, M. et al. (2017) Building capacity in biodiversity monitoring at the global scale. Biodiversity and Conservation, 26, 2765-2790.

Secretariat of the Convention on Biological Diversity (2014) Global Biodiversity Outlook 4. Secretariat of the Convention on Biological Diversity, Montréal, Canada.

Stem, C., Margoluis, R., Salafsky, N. \& Brown, M. (2005) Monitoring and evaluation in conservation: a review of trends and approaches. Conservation Biology, 19, 295-309.

STEPHENSON, P.J. (2018) A global effort to improve species monitoring for conservation. Oryx, 59, 412-413.

Stephenson, P.J. (2019) The Holy Grail of biodiversity conservation management: monitoring impact in projects and project portfolios. Perspectives in Ecology and Conservation, 17, 182-192.

Stephenson, P.J., Bakarr, M., Bowles-Newark, N., Kleinschroth, F., Mapendembe, A., Ntiamoa-Baidu, Y. et al. (in press) Conservation science in Africa: mainstreaming biodiversity information into decision-making. In Closing the Knowledge-Implementation Gap in Conservation Science-Evidence Transfer Across Spatiotemporal Scales and Different Stakeholders (eds C. Ferreira \& C.F.C. Klütsch), Wildlife Research Monograph Number 3. Springer, New York, USA.

Stephenson, P.J., Bowles-Newark, N., Regan, E., Stanwell-Smith, D., Diagana, M., Hoft, R. et al. (2017a)
Unblocking the flow of biodiversity data for decision-making in Africa. Biological Conservation, 213, 335-340.

Stephenson, P.J., Brooks, T.M., Butchart, S.H.M., Fegraus, E., Geller, G.N., Hoft, R. et al. (2017b) Priorities for big biodiversity data. Frontiers in Ecology and the Environment, 15, 124-125.

Stephenson, P.J., Burgess, N.D., Jungmann, L., Loh, J., O'Connor, S., Oldfield, T. et al. (2015a) Overcoming the challenges to conservation monitoring: integrating data from in situ reporting and global data sets to measure impact and performance. Biodiversity, 16, 68-85.

Stephenson, P.J. \& Ellis, C. (2017) Conserving Africa's Great Apes: Lessons Learned. conbio.org/groups/sections/africa/act/conservingafricas-great-apes-lessons-learned [accessed 19 February 2021].

Stephenson, P.J., O'Connor, S., Reidhead, W. \& Loh, J. (2015b) Using biodiversity indicators for conservation. Oryx, 49, 396.

Stephenson, P.J. \& Reidhead, W. (2018) Portfolio management: measuring short- and long-term results in WWF. In Project Management Best Practices: Achieving Global Excellence, 3rd edition (ed. H.R. Kerzner), pp. 538-538. Wiley, Hoboken, USA.

Troudet, J., Grandcolas, P., Blin, A., Vignes-Lebbe, R. \& Legendre, F. (2017) Taxonomic bias in biodiversity data and societal preferences. Scientific Reports, 7, 9132.

Velasco, D., García-Llorente, M., Alonso, B., Dolera, A., Palomo, I., Iniesta-Arandia, I. \& Martín-López, B. (2015) Biodiversity conservation research challenges in the 21st century: a review of publishing trends in 2000 and 2011. Environmental Science \& Policy, 54, 90-96.

WWF (2018) Living Planet Report-2018: Aiming Higher (eds M. Grooten \& R.E.A. Almond). WWF, Gland, Switzerland. 